\title{
PRELIMINARY ANALYSIS OF A ROTARY COMPRESSION TEST
}

\author{
Zbigniew Pater', Patrycja Walczuk'1, Konrad Lis' ${ }^{1}$,ukasz Wójcik¹ \\ 1 Lublin University of Technology, 36 Nadbystrzycka Str., 20-618 Lublin, Poland, e-mail: z.pater@pollub.pl, \\ k.lis@pollub.pl, I.wojcik@pollub.pl
}

Received: 2017.12.13

Accepted: 2018.03.14

Published: 2018.06.01

\begin{abstract}
The paper addresses the problem of material fracture in cross rolling processes. A new test based on rotary compression for determining limit values of the damage function after the Cockroft-Latham criterion is proposed. A FEM analysis is performed to determine the stress and strain states in a workpiece subjected to this test. The numerical results demonstrate that the axial region of the workpiece is characterized by the presence of alternating tensile and compressive stresses conducive to fracture. The distribution of the Cockroft-Latham integral in the axial region of the workpiece is determined.
\end{abstract}

Keywords: material fracture, rotary compression test, stress state, strain state, FEM.

\section{INTRODUCTION}

One of the common failure modes in metal forming processes is material fracture that describes limit strains in a given metal forming process. This phenomenon involves a change in the energy of plastic strains leading to cracking of the material that can be described by the so-called ductile fracture criterion:

$$
\int_{0}^{\varepsilon_{f}} \Phi(\sigma) d \varepsilon=C
$$

where: $\Phi$ is the function describing the effect of stress on the rate of formation and connection of cavities, $\varepsilon_{\mathrm{f}}$ is the limit strain, $\mathrm{C}$ is the limit value of the damage function.

An overview of the literature [1-8] reveals that there are many ductile fracture criteria that are based on the function $\Phi(\sigma)$. As regards metal forming processes, the most widely used of the above criteria is the Cockroft-Latham criterion incorporated into most commercial simulation software based on the finite element method. This criterion is described by the equation:

$$
\int_{0}^{\varepsilon_{f}} \frac{\sigma_{1}}{\sigma_{i}} d \varepsilon=C
$$

where: $\sigma_{1}$ is the equivalent stress, $\sigma_{1}$ is the maximal principal stress.

The practical application of the fracture criterion requires the knowledge of the limit value of the damage function $\mathrm{C}$, which is determined via tensile, compression or torsion tests. These tests consists in the use of specimens with specially designed shapes (axisymmetric or flat) in order to accelerate fracture of the material. The research conducted by many scientists demonstrates that fracture depends not only on grain size, temperature and strain rate [1,9-11], but on the state of stress described by a strain history as well $[3,12$ 15]. The main conclusion drawn from the results is that the ductile fracture criterion is well-suited for the modelling of material fracture when the stresses are similar in the test and the investigated process alike.

A frequent failure mode in cross and skew rolling processes is the occurrence of fracture in the axial region of the workpiece, known as the Mannesmann effect [10, 16-18]. The fracture is caused by alternating compressive and tensile stresses that occur in this region and change their sign twice in one rotation of the workpiece. The numerical modelling of this failure mode requires 

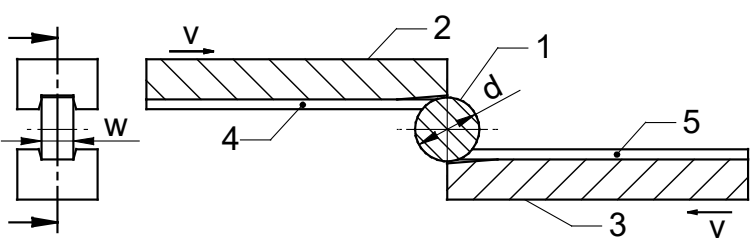

Fig. 1. Schematic design of a rotary compression test

the determination of the limit value of the damage function in close-to-real conditions, as the use of values obtained from tensile and compressive tests for this purpose will produce wrong results. Consequently, it is fully justified to develop new research methods for determining limit values of the damage function under changing loads that are typical of cross wedge rolling and skew rolling processes. In these processes, the stresses in the axial region of the rotated workpiece change alternately from tensile to compressive (twice per one revolution of the workpiece). One of such methods is an innovative rotary compression test developed by Pater. The method has been granted patent protection with the Patent Office of the Republic of Poland [19, 20].

\section{DESIGN OF THE PROPOSED ROTARY COMPRESSION TEST}

The proposed rotary compression test by flat tools (Fig. 1) consists in the following: a cylindrical specimen 1 is positioned in wedge grooves 4 and 5 made on tools 2 and 3 that are spaced by a distance smaller than a diameter $\mathrm{d}$. Next, the tools 2 and 3 are rotated in the opposite directions with the same velocity v. The contrary moving tools 2 and 3 make the specimen 1 rotate and compress it, alternately generating compressive and tensile stresses in its axial region, which leads to fracture. The workability of the material is determined based on the number of revolutions performed by the specimen 1 before fracture. This rotary compression test can also be performed in another way: one of the tools 2 or 3 performs feed motion with a velocity v. As a result, the specimen 1 undergoes rotary compression, while the other remains stationary.

One advantage of the proposed test is that it enables the determination of plastic properties of materials for much wider strain ranges than is possible with previous methods based on uniaxial tension or compression. In addition, the cost of producing specimens for the pro-

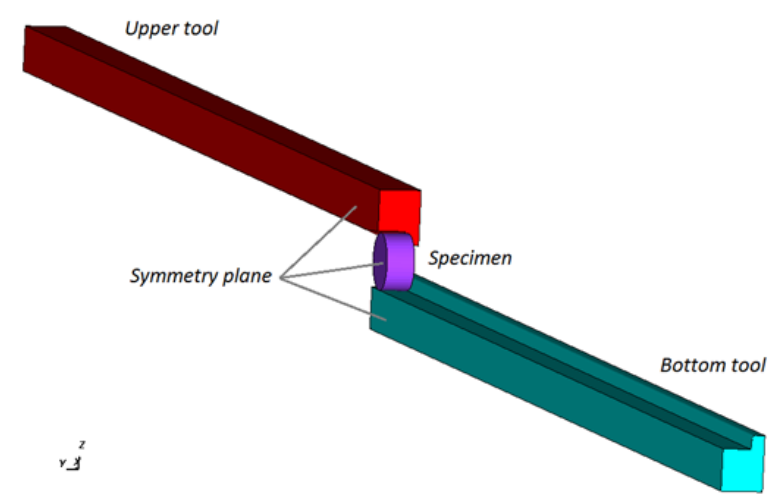

Fig. 2. Geometrical model of the rotary compression process made in Simufact.Forming

posed test is lower than that of specimens used in previous methods. The new test does not require the use of specialist measuring machines - it can be performed using universal machines equipped with tools performing reciprocating motion, such as presses, cross rolling mills, planers and grinders. Another advantage of the test is its universality, hence it is applicable to all wrought metals and alloys.

\section{NUMERICAL MODEL OF THE ROTARY COMPRESSION TEST}

The initial research involved a preliminary numerical analysis of a rotary compression process. The aim of the analysis was to demonstrate that the process is likely to cause ductile fracture. The numerical analysis was performed using a geometrical model of the process made with Simufact.Forming, shown in Fig. 2. According to the design of the process, the lower tool does not move at all, while the upper tool moves with a velocity of $0.3 \mathrm{~m} / \mathrm{s}$ (thereby designed process is feasible to conduct at the Lublin University of Technology). The process is performed on a cylindrical billet with a $20 \mathrm{~mm}$ diameter and a 20
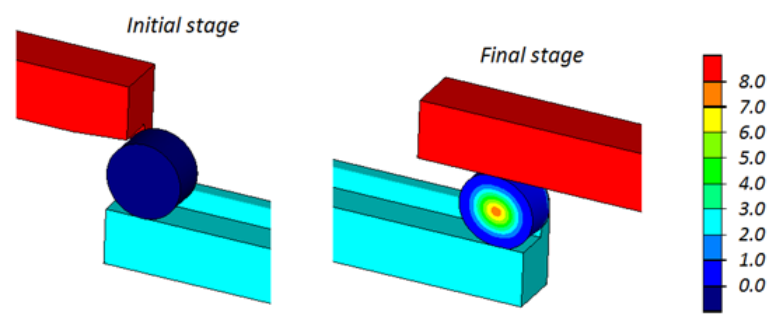

Fig. 3. Damage function determined by the CockroftLatham criterion in symmetry plane of the workpiece under rotary compression 
mm length, assigned the properties of C45 steel. Prior to forming, the billet was heated to the temperature of $1100^{\circ} \mathrm{C}$ and the temperature of the tools was maintained constant at $20^{\circ} \mathrm{C}$. The friction factor on the material-tool contact surface was set to 0.9 and the material-tools heat transfer coefficient was set to $10 \mathrm{~kW} / \mathrm{m}^{2} \mathrm{~K}$.

\section{NUMERICAL RESULTS}

The numerical results confirm the suitability of the proposed rotary compression test for fracture analysis. Fig. 3 illustrates the damage function distribution determined in compliance with the Cockroft-Latham criterion. It can be observed that the function has a ring-shaped pattern, its highest values occurring in the axial region of the workpiece where fracture is most likely to occur. It is worth stressing that the damage function measured with this test is much higher than that obtained from standard tension or compression tests.

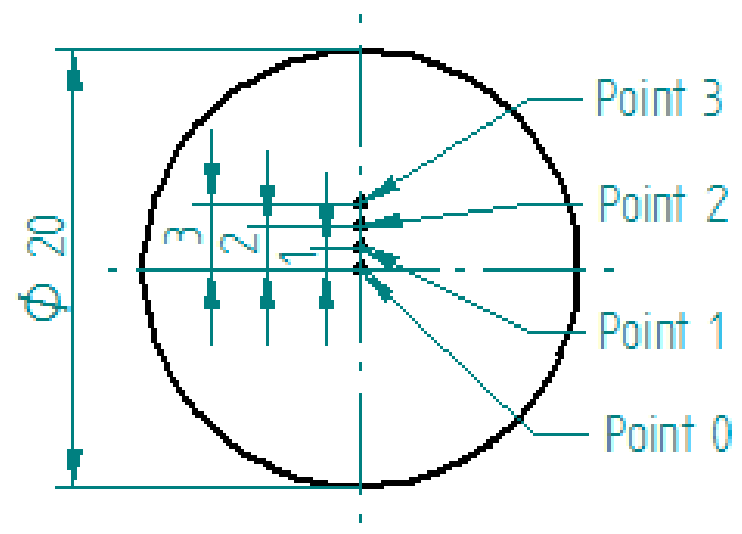

Fig. 4. Location and denotation of measuring points in the workpiece

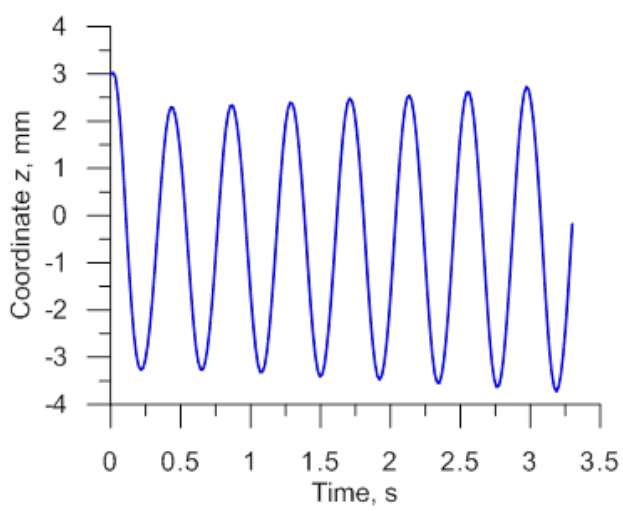

Fig. 5. Point 3 vertical coordinate in rotary compression
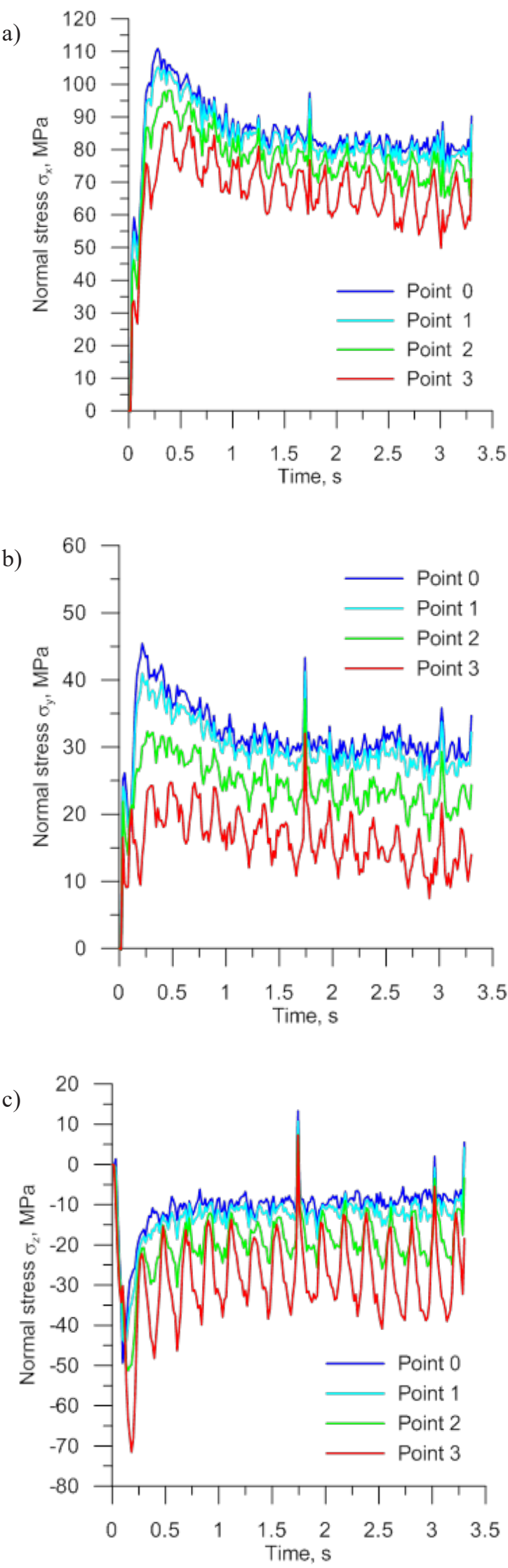

Fig. 6. Normal stress at selected measuring points on the workpiece in directions: a) $\mathrm{x}$ (in accordance with tool motion), b) y (perpendicular to symmetry plane), c) z (vertical) 


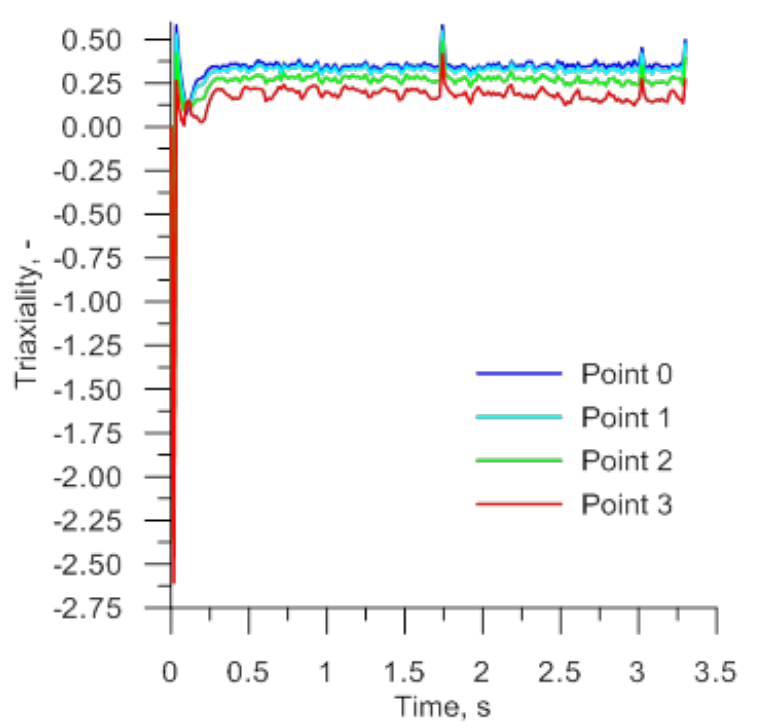

Fig. 7. Stress triaxiality at measuring points in rotary compression

To obtain accurate data about the stresses and strains in rotary compression, four points were marked in symmetry plane of the workpiece, their initial distance from the workpiece axis being 0 $\mathrm{mm}$ (Point 0), $1 \mathrm{~mm}$ (Point 1), $2 \mathrm{~mm}$ (Point 2) and $3 \mathrm{~mm}$ (Point 3), respectively - Fig. 4. The stresses and strains in these measuring points were thoroughly analysed.

Fig. 5 illustrates the changes in the coordinate $\mathrm{z}$ at Point 3 during the compression process. It can be observed that the changes occur cyclically, which is caused by rotation of the workpiece. The results demonstrate that under the applied variables, the workpiece is rotated 7.75 times, undergoing 15 forming cycles.

We also obtain important information from an analysis of the normal stresses acting in the following directions: $x$ - corresponding to the direction of tool motion (Fig. 6a), y - perpendicular to symmetry plane (Fig. 6b), z - vertical (Fig. 6c). Throughout the whole forming process the measuring points exhibit the presence of stress triaxiality that is characterized by two tensile stresses $\left(\sigma_{x}\right.$ and $\left.{ }_{y}\right)$ and one compressive stress $\left(\sigma_{z}\right)$. The closer these points are to the centre line of the workpiece, the higher the tensile stresses and the lower the compressive stresses become (not to mention that the variations in these stresses decrease). The results demonstrate that the rotary compression process is dominated by the tensile stresses leading to fracture, as is clearly visible from the stress triaxiality distribution in Fig. 7.

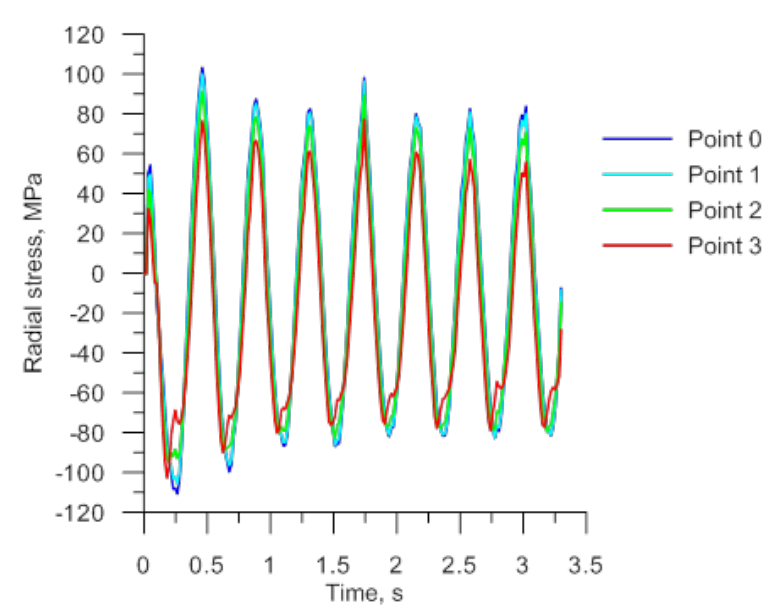

Fig. 8. Radial stress at measuring points in radiallyoriented layer of the workpiece

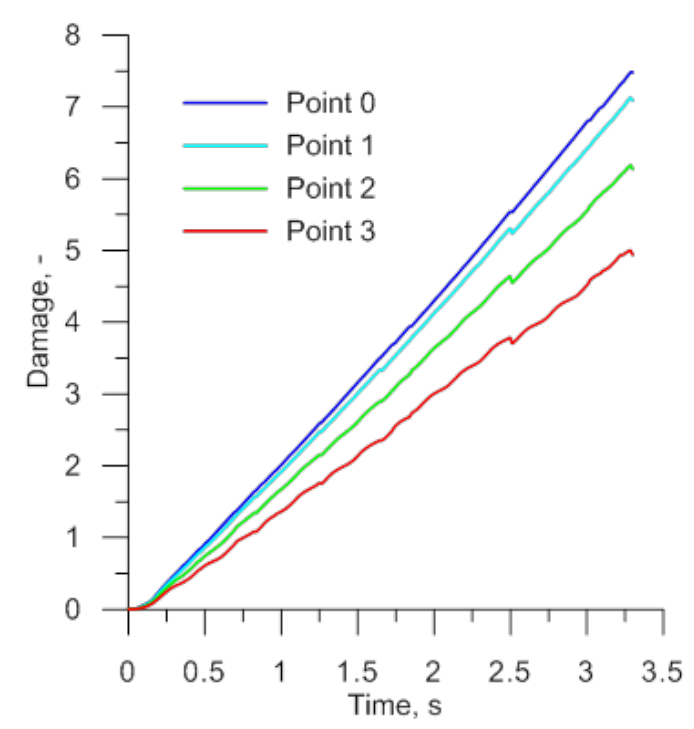

Fig. 9. Damage function according to the CockroftLatham criterion at measuring points in rotary compression

The relatively late initiation of fracture (at high damage function values) in the rotary compression process is accounted for by cyclic variations in the state of stress, i.e., alternate compression and tension of the material. To confirm this, radial stresses were measured, i.e., the stresses in the layer that initially goes through selected measuring points $(0,1,2$ and 3$)$ and rotates together with the workpiece in rotary compression. The variations in the radial stresses illustrated in Fig. 8 clearly confirm that the adopted assumptions were correct. At the same time, the results reveal that the amplitude of the radial stresses is the highest in the axis of the workpiece, decreasing with the distance from the workpiece centre. 
Fig. 9 illustrates an increment of the damage function (according to the Cockroft-Latham criterion) at the measuring points of the workpiece. The results demonstrate that the increment is practically monotonic. In addition, it can be observed that the function has the highest value in the centre line of the workpiece; its value decreases with the distance from the axis of the workpiece.

Despite a relatively low thermal capacity of the material, the workpiece does not undergo cooling in the vicinity of its axial region; on the contrary, its temperature increases (Fig. 10). This is due to the fact that this region is deformed very rapidly (tangential metal flow is dominant), and $90 \%$ of deformation work is converted into heat. Naturally, the observed increase in the temperature should be taken into account when determining the parameters of rotary compression corresponding to the moment of fracture.

\section{CONCLUSIONS}

The paper was a preliminary analysis of a new rotary compression test for determining the limit value of damage function. The FEM results of the test lead to the following conclusions:

- the damage function has a ring-shaped pattern of distribution in the workpiece, reaching the highest values in its axial region where material fracture should occur;

- the damage function in the rotary compressed workpiece reaches much higher values than those obtained from tensile or compression tests;

- the increment of the damage function in the axial region of the workpiece is monotonic;

- the axial region of the workpiece is dominated by the tensile stresses leading to material fracture;

- despite its relatively low thermal capacity, the material does not undergo cooling in the axial region of the workpiece; on the contrary, its temperature increases.

\section{ACKNOWLEDGMENT}

The research has been conducted under the project No. 2017/25/B/ST8/00294 financed by the National Science Centre, Poland.

\section{REFERENCES:}

1. Kim S. W., Lee Y. S., Comparative Study on Failure Prediction in Warm Forming Processes of $\mathrm{Mg}$ Alloy Sheet by the FEM and Ductile Fracture Cri- teria. Metallurgical and Materials Transactions B 45B (2014) 445-453.

2. Li H., Fu M. W., Lu J., Yang H., Ductile fracture: Experiments and computations. International Journal of Plasticity 27 (2014) 147-180.

3. Yan Y., Wang H., Wan M., Prediction of fracture in press bend forming of aluminum alloy highstiffener integral panels. Computational Materials Science 50 (2011) 2232-2244.

4. Wu Z., Li S., Zhang W., Wang W., Ductile fracture simulation of hydropiercing process based on various criteria in 3D modeling. Materials and Design 31 (2010) 3661-3671.

5. Otzurk F., Lee D., A New Methodology for Ductile Fracture Criteria to Predict the Forming Limits. Journal of Materials Engineering and Performance 62 (2007) 2 224-228.

6. Otzurk F., Lee D., Analysis of forming limits using ductile fracture criteria. Journal of Materials Processing Technology 147 (2004) 397-404.

7. Hambli R., Reszka M., Fracture criteria identification using an inverse technique method and blanking experiment. International Journal of Mechanical Sciences 44 (2002) 1349-1361.

8. Kraisnik M., Vilotic D., Sidanin L., Stefanovic M., Various Approaches to Defining the Criteria of Ductile Crack in Cold Bulk Forming Processes. Annals of Faculty Engineering Hunedoara - International Journal of Engineering 13 (2015) 2 213-218.

9. Wang Z., Sun S., Wang B., Shi Z., Fu W., Importance and role of grain size in free surface cracking prediction of heavy forgings. Materials Science \& Engineering A 625 (2015) 321-330.

10. Novella M. F., Ghiotti A., Bruschi S., Bariani P. F., Ductile damage modeling at elevated temperature applied to the cross wedge rolling of AA6082-T6 bars. Journal of Materials Processing Technology 222 (2015) 259-267.

11. Kim H. K., Kim W. J., Failure prediction of magnesium alloy sheets deforming at warm temperatures using the Zener-Holloman parameter. Mechanics of Materials 42 (2010) 293-303.

12. Bjorklund O., Govik A., Nilsson L., Prediction of fracture in a dual-phase steel subjected to nonlinear straining. Journal of Materials Processing Technology 214 (2014) 2748-2758.

13. Yu S., Feng W., Experimental research on ductile fracture criterion in metal forming. Frontiers of Mechanical Engineering 6 (2011) 3 308-311.

14. Coppola T., Cortese L., Folgarait P., The effect of stress invariants on ductile fracture limit in steels. Engineering Fracture Mechanics 76 (2009) 1288-1302.

15. Goijarets A. M., Govaert L. E., Baaijens F. P. T., Evaluation of ductile fracture models for different 
metals in blanking. Journal of Materials Processing Technology 110 (2001) 312-323.

16. Zhou J., Yu Z., Zeng Q., Analysis and experimental studies of internal voids in multi-wedge cross wedge rolling stepped shaft. The International Journal of Advanced Manufacturing Technology 72 (2014) 1559-1566.

17. Yang C., Zhang K., Hu Z., Development of central minute cavity in the workpiece of cross wedge rolling. Applied Mechanics and Materials 215-216 (2012) 766-770.
18. Pater Z., Cross-Wedge Rolling. In Comprehensive Materials Processing, Ed. Elsevier Ltd., Vol. 3 (2014) 211-279.

19. Pater Z. Sposób wyznaczania właściwości plastycznych materiałów metodą obciskania obrotowego narzędziami płaskimi. Patent RP nr 220786 (2014-11-05)

20. Pater Z. Sposób wyznaczania własności plastycznych materiałów metodą obciskania obrotowego dwoma walcami. Patent RP nr 220753 (2015-05-08). 